\title{
Cycles of chromosome instability are associated with a fragile site and are increased by defects in DNA replication and checkpoint controls in yeast
}

\author{
Anthony Admire, ${ }^{1,2}$ Lisa Shanks, ${ }^{1}$ Nicole Danzl, ${ }^{1,3}$ Mei Wang, ${ }^{4}$ Ulli Weier, ${ }^{4}$ William Stevens, ${ }^{1}$ \\ Elizabeth Hunt, ${ }^{1}$ and Ted Weinert ${ }^{1,5}$ \\ ${ }^{1}$ Department of Molecular and Cellular Biology, University of Arizona, Tucson, Arizona 85721, USA; ${ }^{2}$ Department of \\ Surgery, Division of Plastic Surgery, Saint Louis University, St. Louis, Missouri 63104, USA; ${ }^{3}$ Department of Pharmacology, \\ Columbia University Medical Center, New York, New York 10032, USA; ${ }^{4}$ Lawrence Berkeley National Laboratory, \\ Berkeley, California 94720, USA
}

\begin{abstract}
We report here that a normal budding yeast chromosome (ChrVII) can undergo remarkable cycles of chromosome instability. The events associated with cycles of instability caused a distinctive "sectoring" of colonies on selective agar plates. We found that instability initiated at any of several sites on ChrVII, and was sharply increased by the disruption of DNA replication or by defects in checkpoint controls. We studied in detail the cycles of instability associated with one particular chromosomal site (the "403 site"). This site contained multiple tRNA genes known to stall replication forks, and when deleted, the overall frequency of sectoring was reduced. Instability of the 403 site involved multiple nonallelic recombination events that led to the formation of a monocentric translocation. This translocation remained unstable, frequently undergoing either loss or recombination events linked to the translocation junction. These results suggest a model in which instability initiates at specific chromosomal sites that stall replication forks. Forks not stabilized by checkpoint proteins break and undergo multiple rounds of nonallelic recombination to form translocations. Some translocations remain unstable because they join two "incompatible" chromosomal regions. Cycles of instability of this normal yeast chromosome may be relevant to chromosome instability of mammalian fragile sites and of chromosomes in cancer cells.
\end{abstract}

[Keywords: Chromosome instability; checkpoints; fragile sites]

Supplemental material is available at http://www.genesdev.org.

Received January 3, 2005; revised version accepted November 22, 2005.

Chromosomal instability leading to chromosome rearrangements and loss plays an important role in evolution and in cancer (Eichler and Sankoff 2003; Vogelstein and Kinzler 2004). Chromosomal instability is normally suppressed by specific proteins that interact with specific DNA sequence elements. For example, mismatch repair proteins prevent repeat sequences from undergoing sequence expansion or contraction (Kolodner and Marsischky 1999). Telomeric proteins prevent telomeres from fusing and undergoing events of the breakagefusion-bridge cycle that can lead to large-scale chromosomal rearrangement (van Steensel et al. 1998; de Lange 2002, 2005). In yeast, the Sir2 protein suppresses rearrangements between repeats in the rDNA locus (Bitterman et al. 2003).

${ }^{5}$ Corresponding author.

E-MAIL tweinert@u.arizona.edu; FAX (520) 621-3709.

Article published online ahead of print. Article and publication date are at http://www.genesdev.org/cgi/doi/10.1101/gad.1392506.
Specific proteins also suppress instability at chromosomal sites that disrupt DNA replication. Mammalian fragile sites are chromosomal sites prone to break when DNA replication is disrupted (Richards 2001); why these sites are prone to breakage remains unclear. Instability of a fragile site can lead to recombination that activates oncogenes (Coquelle et al. 1997; Hellman et al. 2002). Chromosomal sites in yeast that behave like mammalian fragile sites have also been reported (Cha and Kleckner 2002; Lemoine et al. 2005).

The DNA damage and replication checkpoint proteins represent a major class of regulatory proteins that are highly conserved and preserve genome-wide and sitespecific stability (Zhou and Elledge 2000; Nyberg et al. 2002; Kolodner et al. 2002; Kastan and Bartek 2004). Budding yeast checkpoint proteins may preserve stability by regulation of cell cycle progression or of DNA replication (e.g., the regulation of dNTP levels, origin firing after damage, and replication fork stability) (Desany et 
al. 1998; Santocanale and Diffley 1998; Zhao et al. 1998; Lopes et al. 2001; Tercero and Diffley 2001). Mammalian checkpoint proteins likely have similar roles (Lukas et al. 2004). For example, it has been shown that both yeast and mammalian checkpoint proteins stabilize fragile sites, perhaps by stabilizing replication forks (Casper et al. 2002; Arlt et al. 2004; Lemoine et al. 2005; this study), and how they do so is unclear.

Chromosome intermediates formed during genome rearrangements have not been extensively documented. Unstable chromosomes include those containing triplet nucleotide repeats (e.g., fragile X) (Richards 2001), two centromeres (dicentric chromosomes) (Gisselsson et al. 2000; Maser and DePinho 2002), and other more poorly understood chromosomes ("jumping translocations") (Padilla-Nash et al. 2001). In this report we find that unstable chromosomes can form frequently and suggest that such intermediates may be a common feature of instability.

Here we examine chromosome instability using a budding yeast strain containing an extra genetically marked normal chromosome (Chromosome VII [ChrVII]). This well-marked chromosome allowed us to genetically track its instability. Loss of a marker gene $\left(C A N 1^{+}\right)$identified cells that had undergone a chromosome change. Many cells that had lost the $C A N 1^{+}$gene generated distinctive sectored colonies that proved to contain unstable chromosomes undergoing cycles of instability. Cells with unstable chromosomes were detected at low frequency in unperturbed normal cells $\left(\sim 1\right.$ in $10^{6}$ cells $)$, at a very high frequency $\left(\sim 1\right.$ in $10^{3}$ cells $)$ in cells with defects in DNA replication and in replication checkpoint genes. Instability frequently involved one particular site, the "403 site." Instability of this site frequently generated a specific unstable chromosome that is monocentric yet remained unstable, and was eventually lost or stabilized by allelic recombination. We infer that unstable chromosomes with similar genetic properties occurred at other chromosomal sites. We propose that replication forks stall at specific sites, forks break unless protected by replication checkpoint controls, and a broken fork can then undergo nonallelic recombination events to form unstable translocations that continue to rearrange.

\section{Results}

\section{The ChrVII assay}

We previously tested the role of the DNA damage checkpoint gene $R A D 9$ in regulating chromosome stability using a haploid yeast strain containing an extra copy of ChrVII (Fig. 1A; Carson and Hartwell 1985; Weinert and Hartwell 1990; Moore et al. 2000; Galgoczy and Toczyski 2001; Ivessa et al. 2003). One of the ChrVII homologs contains a copy of the CAN1 gene inserted $25 \mathrm{~kb}$ from the left telomere, and the normal CAN1 gene on Chromosome $\mathrm{V}(\mathrm{ChrV})$ was mutated to an inactive form. The CAN1 gene encodes arginine permease, a membrane protein that imports arginine as well as the toxic analog
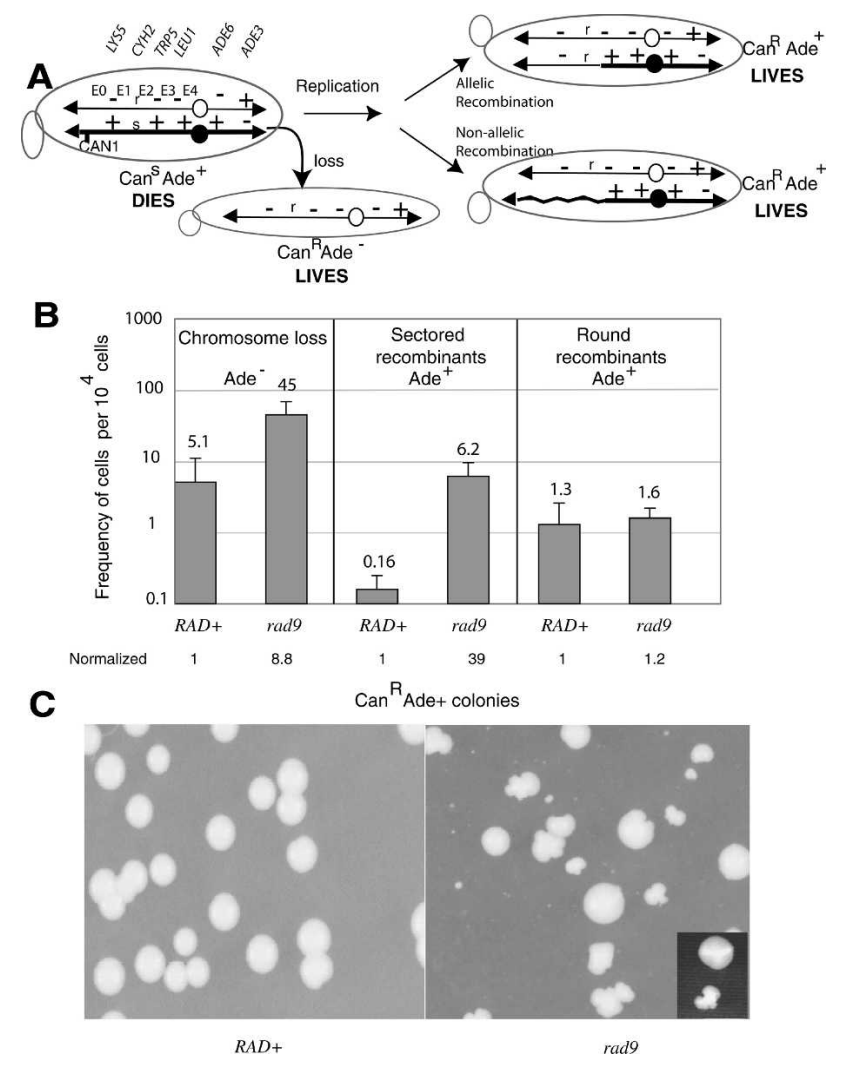

Figure 1. The ChrVII assay reveals elevated chromosome loss and sectored recombinants in a rad9 mutant. (A) The ChrVII system. The two homologs are shown with their genetic markers, the position of the CAN1 gene, the centromeres (filled and open circles), and the five genetic intervals of recombination (E0 through E4). Telomeres are black triangles. A possible mechanism of chromosome loss involves loss of the bottom homolog. A possible mechanism of mitotic recombination involves an event in which the chromosomes replicate, followed by either allelic recombination between homologs to form a normal mitotic recombinant, or nonallelic recombination to generate a translocation. The structures of chromosomes in three cells and their phenotypes are shown. See text. (B) rad9 mutants have a higher frequency of chromosome loss and sectored recombinants than do $R A D^{+}$cells. Frequencies and standard deviations were determined from the average of six to 10 cultures. Absolute numbers of cells per $10^{4}$ cells tested are given. Below are the frequencies normalized to that for $R A D^{+}$. (C) $R A D^{+}$and rad9 cells form round and sectored colonies. Cells were plated on selective media containing canavanine without adenine. Colonies were visible after $5-7 \mathrm{~d}$ of incubation at $30^{\circ} \mathrm{C}$. The inset shows a typical round and sectored colony.

canavanine, so the CAN1 allele confers canavanine sensitivity $\left(\mathrm{Can}^{\mathrm{S}}\right)$. Cells that lose the CAN1 gene are selected by their canavanine resistance. The two ChrVII homologs contain genetic markers that determine if loss of the CAN1 gene occurred by any of several mechanisms (Fig. 1A). For example, a $\mathrm{Can}^{\mathrm{R}} \mathrm{Ade}^{-}$cell would have lost the CAN1 gene by whole chromosome loss, while a $\mathrm{Can}^{\mathrm{R}} \mathrm{Ade}^{+}$cell would have lost the CAN1 gene either by allelic or by nonallelic recombination events. (Other mechanisms of CAN1 loss may also occur.) Mi- 
totic recombination events prove to be particularly interesting. Recombination occurs in any of five genetic exchange intervals (labeled E0 through E4). For example, a $\mathrm{Can}^{\mathrm{R}} \mathrm{Ade}^{+}$cell that is $\mathrm{Lys}^{-} \mathrm{Cyh}^{\mathrm{R}} \mathrm{Trp}^{+} \mathrm{Leu}^{+}$would have been generated by a recombination event between $C Y H 2$ and TRP5 in the E2 genetic interval (see allelic and nonallelic recombinants in Fig. 1A).

\section{Chromosomal changes occur at a higher frequency in rad9 than in $\mathrm{RAD}^{+}$cells}

Rad9 is a checkpoint protein that has several roles in the cell cycle and is required to maintain genome stability (Weinert and Hartwell 1990; Klein 2001; Nyberg et al. 2002). To further define how Rad9 maintains genome stability, we tested the effect of a rad9 mutation on chromosome changes to ChrVII. $R A D^{+}$and rad9 cells were allowed to grow and divide under nonselective growth conditions that permit chromosome changes. Cells were plated on media containing canavanine to select $\mathrm{Can}^{\mathrm{R}}$ colonies with chromosome changes that were then analyzed for the type of change.

We found that the most frequent form of chromosome change in rad9 mutants was chromosome loss, which was approximately ninefold higher in rad9 mutants than in $R A D^{+}$cells as expected from previous studies (Fig. 1B; see Weinert and Hartwell 1990). Unexpected were the results of chromosome change that occurred by mitotic recombination (to form $\mathrm{Can}^{\mathrm{R}} \mathrm{Ade}^{+}$colonies). We identified two types of morphologically distinct $\mathrm{Can}^{\mathrm{R}} \mathrm{Ade}^{+}$ colonies termed "round" and "sectored" (Fig. 1B,C, inset). The round colonies had a uniform appearance, occurred with similar frequencies in rad9 mutant and $R A D^{+}$cells (Fig. $1 \mathrm{~B}$ ), and were formed by recombination in the five genetic intervals at nearly expected frequencies (Supplementary Fig. S1). In contrast, the sectored colonies had an uneven appearance (Fig. 1C, inset), occurred at an $\sim 39$-fold higher frequency in rad9 mutants than in $R A D^{+}$cells (Fig. $1 \mathrm{~B}$ ), and were formed by recombination that occurred most frequently in the E2 genetic interval (Supplementary Fig. S1; see Fig. 2). We show below that a specific site in the E2 genetic interval causes $\sim 60 \%$ of the chromosome instability leading to sectored colonies.

\section{Sectored colonies contain chromosomes undergoing cycles of instability}

It seemed likely that the round and sectored colonies contained cells with recombinant ChrVIIs with distinctive properties. To extend our study of the recombinant ChrVIIs, we performed the lineage analyses shown in Figure 2A. To understand our findings, consider the fates of two hypothetical "founder" cells (hatched or clear). Each founder had lost the $C A N 1^{+}$gene but retained the rest of the extra chromosome just prior to plating on the selection plate. One cell forms a round colony and one a sectored colony. To form these colonies, each $\mathrm{Can}^{\mathrm{R}} \mathrm{Ade}^{+}$ founder cell underwent many cell divisions. We found that a founder cell that had a stable recombinant ChrVII (e.g., hatched cell) generated cells with homogeneous phenotypes (hatched phenotype) in a round colony. In contrast, a founder cell that had an unstable recombinant ChrVII (e.g., clear cell) generated progeny with heterogeneous phenotypes (clear, black, or gray phenotypes) in a sectored colony. We determined the phenotypes of the progeny cells, derived from each founder cell, by resuspending the progeny cells and allowing each to form a colony on an analytical plate. The phenotypes of those colonies were determined, and indicated the phenotypes of individual cells in the sectored colony (see Materials and Methods).

Using this lineage analysis we found that round colonies came from founder cells with a stable recombinant ChrVII (Fig. 2B). Surprisingly, we found that sectored colonies came from founder cells that had a remarkably unstable recombinant ChrVII. For example, while most rad9 round colonies (13 out of 14) contained cells with a homogeneous or nearly homogeneous phenotype (usually $<1 \%$ heterogeneity; colonies 1-3), most sectored colonies (23 out of 24 ) contained cells with highly heterogeneous phenotypes (Fig. 2B). The extent of the heterogeneity was extraordinary. For example, rad9 sectored colony \#4 contained cells with six different phenotypes: E0, E1, E2, and E3 cells, as well as cells that had either lost the chromosome entirely ("loss") or that were "fragmented" (had undergone another chromosomal change while growing on the analytical plate). Because each sectored colony arose from one cell, each founder cell must have undergone many cycles of instability to generate such genetic diversity. We also found that $R A D^{+}$round and sectored colonies also usually contained stable and unstable chromosomes, respectively (Fig. 2B; Supplementary Fig. S1). We conclude that the frequency of instability leading to sectoring is greater in rad9 mutants than in $R A D^{+}$cells, yet the nature of the events are similar in both mutant and wild-type cells.

We next determined if a specific site on ChrVII might be associated with cycles of instability occurring in sectored colonies. Inspection of the data in Figure 2B (rad9 sectored percent) revealed that instability generated E2 cells most frequently; $48 \%$ of sectored cells had undergone a recombination event in the 134-kb E2 interval, compared with $8 \%$ in the $190-\mathrm{kb}$ E0 and $3 \%$ in the $50-\mathrm{kb}$ $\mathrm{E} 3+\mathrm{E} 4$ interval. We conclude that a site in the E2 genetic interval may cause instability and/or be a favored recombinational site. Below we show that, indeed, a specific E2 site causes instability and undergoes recombination during instability events.

The data in Figure 2B also suggest an explanation for why colonies sector. The founder rad9 cell was necessarily $\mathrm{Can}^{\mathrm{R}} \mathrm{Ade}^{+}$, yet $\sim 9 \%$ of the cells formed in the sectored colony had lost one of two ChrVIIs ("loss"). Cells that lose the chromosome on the selective plate will stop dividing because the selective plate does not contain adenine. We therefore believe that the $\mathrm{Can}^{\mathrm{R}}$ $\mathrm{Ade}^{+}$founder cell generated both $\mathrm{Ade}^{+}$progeny that continued to divide and $\mathrm{Ade}^{-}$progeny that stopped dividing, and the uneven colony appearance comes from the continued growth of the $\mathrm{Ade}^{+}$cells next to nondividing $\mathrm{Ade}^{-}$ 
Admire et al.
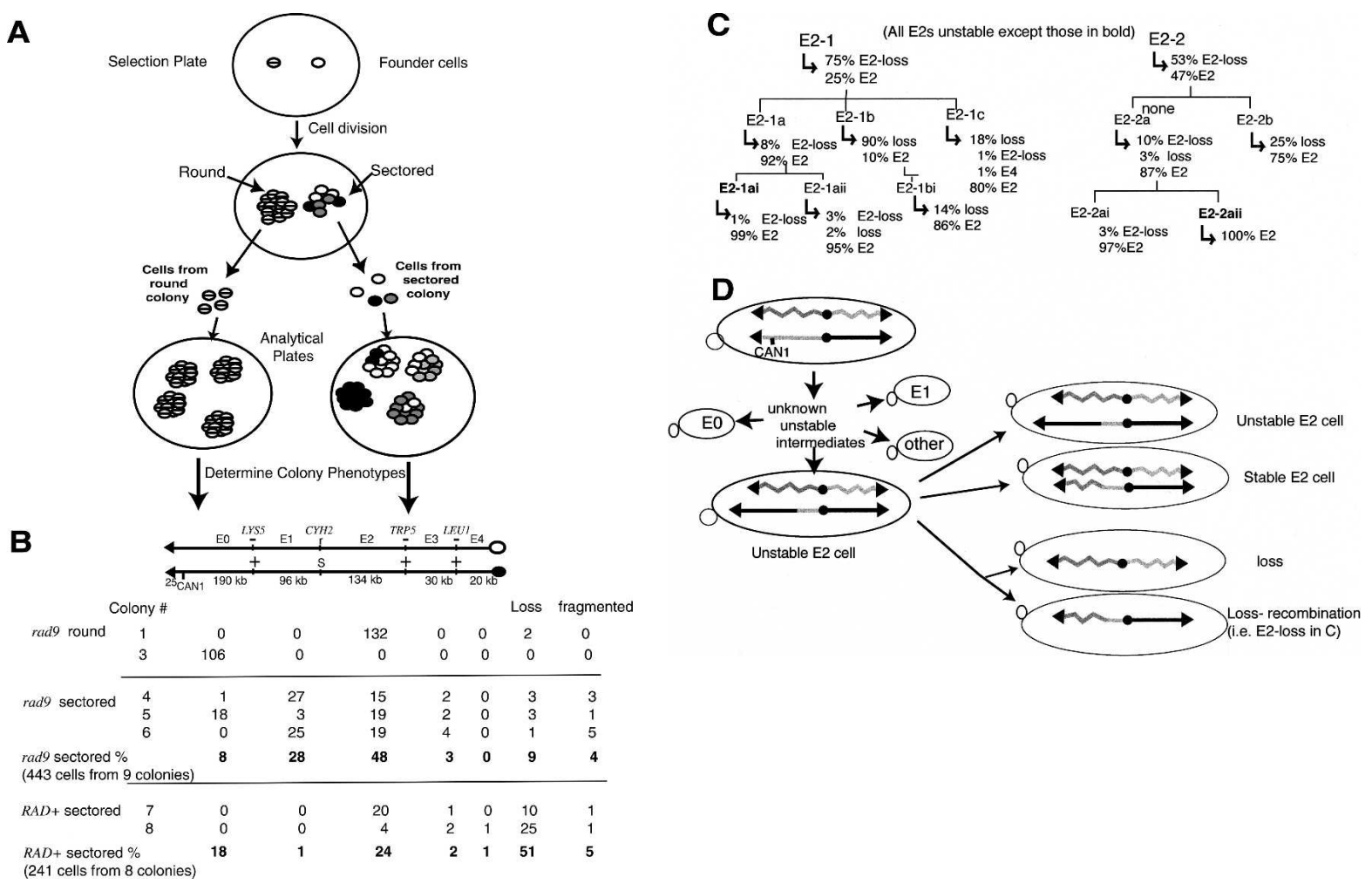

Figure 2. Lineage analyses of unstable ChrVIIs in genetically unstable cells. (A) The logic and methodology of the lineage analysis. Two cells (hatched and open) were plated on the selection plate containing canavanine and not containing adenine. The two cells generate a round and a sectored colony, respectively. The phenotypes of individual cells in each colony were determined as shown (see text and Materials and Methods). Because the hatched founder cell was genetically stable, it generated a round colony, and consequently colonies on the analytical plate of one phenotype. Because the open founder cell was unstable, it generated a sectored colony, and consequently colonies on the analytical plate of many different phenotypes (open, gray, black). Note that some colonies on the analytical plates contain cells with heterogeneous phenotypes. If the founder cell on the analytical plate undergoes a genetic change in the first or second cell division, the colony will contain cells of two different phenotypes in two halves of the colony (or in one-fourth and three-fourths of the colony), detectable as a "fragmented" colony (see text). (B) Phenotypes of colonies on analytical plates. The phenotypes of cells from selected colonies that gave rise to a colony on an analytical plate. Phenotypes were determined by selective replica plating. For example, all 132 cells from round colony \#1 gave rise to analytical colonies with an E2 phenotype, while 51 cells from colony \#4 gave rise to colonies of six different phenotypes. A total of 443 cells from nine sectored rad9 colonies were analyzed, and the absolute numbers and percent of each colony phenotype are shown. Percentages were rounded to the nearest integer. See text for more details. $(C)$ Extended lineage analysis of unstable recombinant ChrVIIs in unstable E2 cells. In the lineage analysis to the left, an E2 cell called E2-1 gave rise to cells in which $75 \%$ had lost the chromosome and $25 \%$ had retained the chromosome. Three of those E2 cells were subjected to lineage analysis, and the results are shown. Analysis of a second E2 cell is shown on the right. See text for discussion. $(D)$ Summary of the fates of an unstable ChrVII in a genetically unstable cell. An initial cell with two ChrVII homologs undergoes chromosome changes by multiple undefined steps to form a cell with an unstable ChrVII that has a chromosomal translocation (dasemonstrated in subsequent sections). An unstable E2 ChrVII is shown. A cell with an unstable ChrVII generate cells with further ChrVII rearrangements or loss as shown. See text for discussion.

cells. Consistent with this interpretation, sectored colonies usually do not form on media containing adenine (data not shown). We cannot exclude additional explanations for the sectoring phenotypes (i.e., poor growth of cells undergoing cycles of instability).

\section{The ultimate fate of the unstable chromosomes}

We determined the ultimate fates of unstable chromosomes that occur in cells in sectored colonies by performing an "extended" lineage analysis, typical results of which are shown in Figure 2C. We focused our analyses on the most commonly formed E2 cells. We found that cells from sectored colonies were very frequently themselves still unstable; 38 of 43 cells taken from sectored colonies went on to generate colonies that still contained cells of multiple phenotypes. For example, cell E2-1 and cell E2-2 both were taken from a sectored colony, and each was unstable because it formed a colony that contained E2 cells and cells that had lost the chromosome. Also, the E2 cells formed by E2-1 and E2-2 remained unstable (e.g., E2-1 formed E2-1a that generated colonies with cells having multiple phenotypes). Unstable E2 cells could remain unstable for up to 80 cell divisions ( 20 cell divisions are required to form a colony of $\sim 10^{6}$ cells on the selection plate and on each succes- 
sive analytical plates). Two E2 cells appear to have become stable in lineages in Figure 2C (E2-1ai and E2-2aii).

In Figure 2D, we provide an interpretation of the genetically determined cycles of instability. An initial cell undergoes chromosome change(s) that lead to loss of the CAN1 gene and the formation of unstable chromosome intermediates. These unstable intermediates rearrange by unknown mechanisms to generate a plethora of recombinants (e.g., E0, E1, E2 cells). We do not yet know the structures of most unstable chromosome intermediates, but we do know a structure of one unstable intermediate that gives rise to E2 cells. This unstable intermediate, as described below, has a specific translocation as indicated in Figure 2D.

We can infer the fates of unstable E2 cells from data shown in Figure 2B and C. Unstable E2 cells undergo additional cell divisions in which the unstable chromosome was either retained, formed a stable chromosome by allelic recombination (with the homolog), or underwent chromosome loss. That unstable E2 chromosomes persist is shown by the lineages in Figure 2C. That unstable chromosomes eventually become stable is indicated by the observation that five of 43 cells from sectored colonies were stable (two stable E2 cells in Fig. 2C; see below). That unstable E2 cells form stable E2 cells, probably by allelic recombination, comes from the observation cited below (an altered chromosome in unstable E2 cells is replaced by a normal chromosome). The unstable E2 cells also give rise to cells that have lost the chromosome, and loss occurs by either of two mechanisms; either as loss or as loss coupled to recombination. Multiple examples of loss and loss coupled to recombination are indicated in Figure 2C ("loss" and "E2-loss," respectively; E1-loss and E3-loss events in other lineages have also been detected) (data not shown). Finally, the rates of these changes to the unstable chromosomes can at present only be inferred. From the frequencies of chromosome loss and fragmented colonies in sectored colonies $(9 \%$ and $4 \%$, respectively) (Fig. $2 B)$, and from inspection of lineage analyses in Figure 2C, we infer that unstable chromosomes rearrange or are lost in about one in 20 cell divisions, $\sim 10$-fold more frequently than the initial ChrVII. Quantitative tests of the rates of chromosome change will become possible with knowledge of the structures of unstable chromosomes.

\section{Unstable chromosomes frequently have an altered size}

It seemed likely that the phenotypically unstable chromosomes had suffered genome rearrangements. To investigate the physical structures of unstable chromosomes, we prepared genomic DNA from unstable (sectored) and stable (round) rad9 colonies and analyzed whole chromosomes by pulsefield gels (see Materials and Methods) (Fig. 3). The entire analysis shown in Figure 3 is of chromosomes from rad9 cells. Chromosomes from the initial ChrVII rad9 strain and from stable Can ${ }^{\mathrm{R}} \mathrm{Ade}^{+}$ mitotic recombinants were of the expected sizes $(N=20)$ (Fig. 3A, lanes 1,7,10). In contrast, chromosomes from

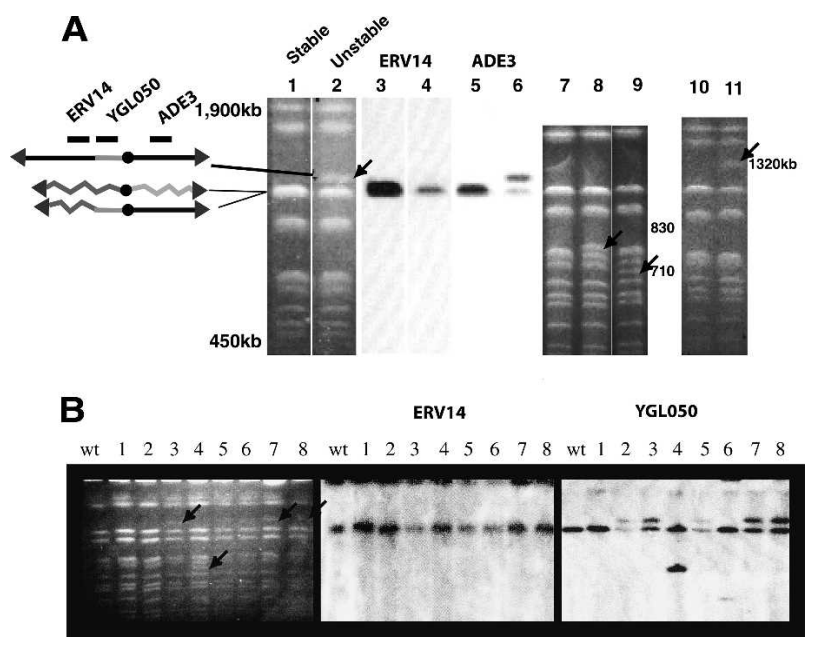

Figure 3. Unstable cells contain a chromosome of altered size. Chromosomes were prepared from rad9 sectored colonies as described in Materials and Methods, separated on pulsefield gels, and visualized by staining with EtBr or by autoradiography after Southern hybridization. (A) Chromosomes from stable round colonies (lanes $1,3,5,7,10)$ and from unstable sectored colonies (lanes 2,4,6,8,9,11) were stained with EtBr (lanes 1,2,711) or probed with sequences that detect ERV14 (lanes 3,4) or $A D E 3$ (lanes 5,6$)$. Chromosomes of altered size are indicated by arrows. (B) Chromosomes from the initial rads strain (wt) and from eight independent sectored rad9 colonies (lanes 1-8). Chromosomes were stained with EtBR (left panel), or hybridized with probes that detected ERV14 (middle panel) or YGLO50 (right panel). No altered chromosomes were detected in lane 1.

unstable colonies frequently (30 out of 96) contained chromosomes of the expected sizes plus a chromosome of an altered size (Fig. 3A, lanes 2,8,9,11). (We believe most of the 66 unstable colonies contained an altered chromosome that was difficult to detect because of its scarcity and/or heterogeneity; see below.) Of the 30 strains in which we detected an altered chromosome on pulsefield gels, 29 came from cells with an E2 phenotype, and in 22 of those altered chromosomes were $\sim 1200 \mathrm{~kb}$ in size (Fig. 3A [lanes 1,2], B [lanes 2,3,5,7,8, arrows]).

We determined the structures of the $\sim 1200-\mathrm{kb}$ altered E2 chromosomes by Southern hybridization using DNA probes from the E2 region (data not shown). Probes from the two genes ERV14 and YGL050, which are $4 \mathrm{~kb}$ apart, proved most informative (Fig. 3A,B). The altered E2 $1200-\mathrm{kb}$ chromosomes always hybridized with a probe to the YGL050 gene but not to the ERV14 gene $(N=13)$ (Fig. $3 \mathrm{~A}, \mathrm{~B})$. This suggests that all 13 unstable E2 chromosomes analyzed had lost DNA from ERV14 to the left end of the chromosome, consistent with the genetics of an E2 cell (Fig. 1A).

Several unstable chromosomes (eight out of 30) from rad9 strains had sizes that differed from $\sim 1200 \mathrm{~kb}(\sim 710$, 830, 1300, 1400, and $1900 \mathrm{~kb}$ species) (see Fig. 3A [lanes $8,9,11]$, B [lanes 4,6]; data not shown). All but one were from unstable E2 colonies, the exception being a 1300-kb chromosome from an unstable E1 colony /data not shown). By Southern hybridization, the 710- and 830-kb 
altered chromosomes also contained the YGLO50 gene but not the ERV14 gene (Fig. 3B, lanes 4,6); they had the same breakpoint as the $1200-\mathrm{kb}$ chromosomes on the left arm of ChrVII. Further analysis was not performed on the smaller chromosomes because one was lost and the other was converted into the common 1200-kb species upon subsequent cell propagation (data not shown). (Instability resulting in loss or allelic recombination was common. For example, 18 out of 18 unstable E2 cells converted their altered chromosomes to one of the normal size for ChrVII when cells were propagated in media lacking adenine [data not shown]. We infer that these cells underwent an allelic mitotic recombination event to generate two normal-sized ChrVIIs.) We conclude that unstable E2 chromosomes often contain a physically altered chromosome that has a breakpoint in the region between ERV14 and YGLO50 (which is $4 \mathrm{~kb}$ in size). We call this 4-kb region the "403 E2 site" because it is centered in the E2 genetic interval $403 \mathrm{~kb}$ from the normal left end of ChrVII. The unstable chromosomes are either lost or converted, probably by allelic recombination, to a normal-sized ChrVII.

DNA sequence analysis of breakpoint junctions defines an $\sim 500-k b$ translocation

Because many altered chromosomes were $\sim 1200 \mathrm{~kb}$ in size but had lost $\sim 400 \mathrm{~kb}$ of DNA for the 403 site to the left end of ChrVII, they must have acquired $\sim 500 \mathrm{~kb}$ of unknown DNA from elsewhere in the genome. We identified the source of the $\sim 500-\mathrm{kb}$ DNA by isolating DNA fragments that span the breakpoint junction (joining the 403 E2 site to the unknown DNA; see Materials and Methods). Using a PCR-based strategy, we obtained DNA fragments of similar sizes from three unstable E2 colonies (Fig. 4A) and determined their DNA sequences. All three breakpoint junctions were identical, and the sequence suggested a simple model for how the 1200-kb altered chromosome was formed (Fig. 4B). (Two of the three breakpoint junction samples had exactly this DNA sequence, and the third sequence was incomplete yet consistent with this sequence.)

The $\sim 1200-\mathrm{kb}$ altered chromosome contained a chromosome duplication in which the 403 E2 site was fused to a site at $535 \mathrm{~kb}$ on the right arm of ChrVII (Fig. 4B). This product of a chromosomal duplication and translocation we call the "403-535" chromosome. The DNA sequence of the breakpoint junction indicated that the 403-535 chromosome was likely the consequence of not one but two recombination events, each between short repeat LTR (long terminal repeat) sequences. (LTR sequences derive from the ends of Ty1 and Ty3 retrotransposons.) The recombination events fused two $\sigma$ sequences (S2 and S3, 278 and 245 base pairs (bp), respectively, sharing $80 \%$ identity) and two $\delta$ sequences (D7 and D11, 331 bp sharing 97\% identity). The model shown is the simplest we could devise to explain the recombination breakpoint junction sequence.

The structure of the 403-535 chromosome is important because it may provide insight into the nature of
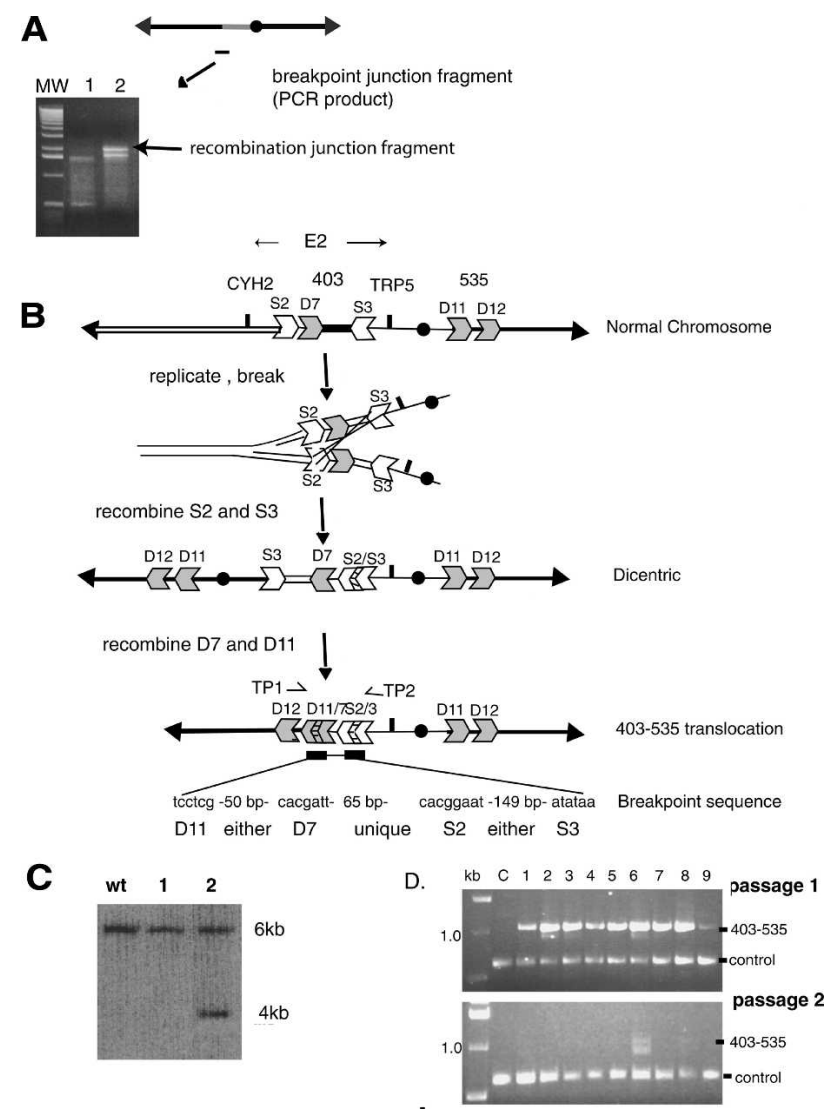

Figure 4. Isolation and analysis of the DNA sequence of the recombination junction, and a model indicating how the altered chromosome was formed. (A) A PCR technique was used to generate DNA fragments that contain the breakpoint junction (see Materials and Methods). PCR fragments are shown from the original rad9 strain (lane 1) and from one rad9 sectored E2 colony (lane 2; gel images). A ladder of molecular weight standards is shown. The junction fragment is $\sim 2 \mathrm{~kb}$ in size. (B) Interpretation of the structure of the recombination junction. The normal chromosome contains LTR sequence fragments (S2, D7, S3, D11, and D12). The DNA sequence of the breakpoint junction is shown below the 403-535 chromosome. See text for details. (C) Generation of a novel HpaI restriction fragment indicates the presence of the specific 403-535 unstable chromosome. A HpaI digest of DNA from the initial rad9 strain (WT) and from two sectored E2 rad9 colonies (samples 1,2) was hybridized with a probe to the YGLO50 gene (see Fig. 3). Only the preparation in sample 2 has the Hpal fragment predicted by the 403-535 chromosome. (D) PCR of translocation junction. Primers (TP1, TP2 in $B)$ were used to amplify a DNA fragment spanning the junction from genomic DNA isolated from a round colony $(C)$ and from nine independent sectored colonies. Passages 1 and 2 are genomic DNA isolated from sectored colonies expanded to $\sim 10^{9}$ cells (in $8 \mathrm{~mL}$ of minimal media without adenine and tryptophan; passage 1), and then $50 \mu \mathrm{L}$ of each culture expanded again to $\sim 10^{9}$ cells (in $8 \mathrm{~mL}$ ). Control primers were to YGL044 (see Materials and Methods).

cycles of instability. We therefore verified the structure of the 403-535 chromosome by several different methods. First, restriction enzyme digestion and Southern analysis of strains with the $1200-\mathrm{kb}$ altered chromosome 
generated a predicted 4-kb Hpal restriction fragment (in addition to the $6-\mathrm{kb} \mathrm{Hpal}$ fragment derived from the intact homolog) (Fig. 4C). Second, the 403-535 translocation junction predicts the generation of a specific unique DNA sequence that we should be able to amplify by PCR (Fig. 4D) (see Materials and Methods). We detected the predicted $1.0-\mathrm{kb}$ PCR fragment from genomic DNA from nine of nine sectored colonies (Fig. 4D, lanes $1-9$ ), and we did not detect this fragment in genomic DNA from control strains (i.e., a rad9 round mitotic recombinant) (Fig. 4D, lane C). We also used this qualitative PCR test to demonstrate the instability of the 403535 translocation; we could detect the translocation in nine of nine sectored colonies after a first passage of cells, but in only one in nine cultures after a second passage of cells (each passage involves approximately seven additional cell generations).

To further confirm the structure of the 403-535 translocation, we noted that the $\sim 1200-\mathrm{kb}$ size of the 403-535 chromosome predicted the acquisition of $\sim 500 \mathrm{~kb}$ onto the $403 \mathrm{E} 2$ site; the region from the 535 site to the right end of ChrVII is, in fact, $489 \mathrm{~kb}$. Finally, the predicted 403-535 chromosome should contain two chromosome arms that are both derived from the right arm of the normal ChrVII. We used a technique termed fiber FISH that allowed direct visualization of DNA sequences on chromosome fibers (Wang et al. 1996) (see Materials and Methods). We analyzed one preparation of a normal and one of a well-characterized 1200-kb chromosome (that generated a 4-kb Hpal restriction fragment, had the breakpoint junction sequence shown in Fig. 4B, was in cell E2-1b in Fig. 2C, and was unstable). We detected fibers in the two chromosome preparations whose lengths were consistent with the sizes of normal and altered chromosomes ( 1100 and $\sim 1200 \mathrm{~kb}$, respectively) (data not shown). The $\sim 1200-\mathrm{kb}$ chromosome fibers stained uniformly with a ChrVII probe, suggesting they contained mostly if not only ChrVII sequences (Fig. 5A,B). Importantly, the $\sim 1200-\mathrm{kb}$ chromosome fibers contained two right ends, while the normal chromosome fiber had one (because a probe specific for the right chromosome end hybridized to sequences on both ends of the altered chromosome fiber but to one sequence of the normal chromosome fiber) (Fig. 5A; data not shown). Probes specific for the centromere or breakpoint-proximal regions hybridized to a single site on both normal and altered chromosome fibers (Fig. 5B; data not shown).

We conclude that the structure of the 403-535 chromosome proposed in Figure $4 \mathrm{~B}$ is correct. Importantly, this translocation contains but one centromere. We emphasize here that the 403-535 chromosome was formed de novo at a high frequency (in $\sim 1$ in 2000 rad9 cells). We also found that three out of 30 randomly picked sectored colonies contained a detectable 4-kb Hpal restriction fragment diagnostic of the 403-535 translocation (Fig. $4 \mathrm{C}$; data not shown), and using the more sensitive PCR test, we detected the translocation in most sectored colonies (nine out of nine in Fig. 4D; 13 out of 14 in another separate screen of sectored colonies). We conclude that the 403-535 chromosome is formed in many sectored colonies. (Not all instability is due to the 403 site, however; see below.) We were able to preferentially isolate the 403-535 chromosome either because it was generated more frequently and/or because it was more stable than other unstable chromosomes.

\section{A DNA sequence in the 403 E2 site causes instability}

The data presented above show that the sequences in the 403 site undergo at least two nonallelic recombination events to form the 403-535 translocation. We then asked if sequences in the 403 site might cause instability as well. Figure 6 presents a diagrammatical representation of key DNA sequences, including two tRNA genes, five

A

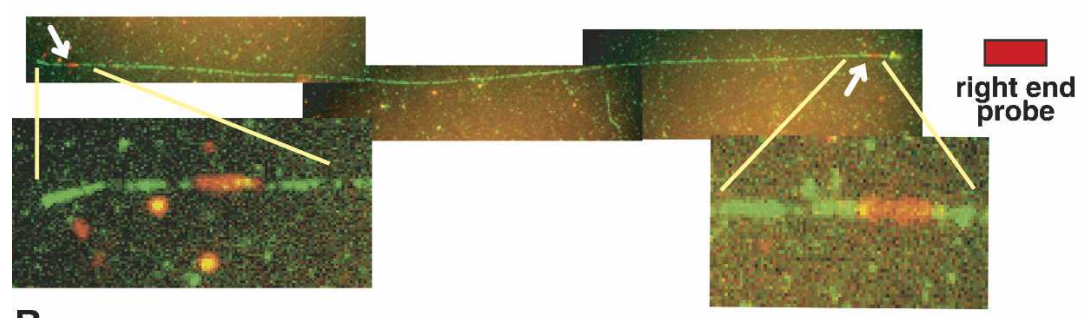

B

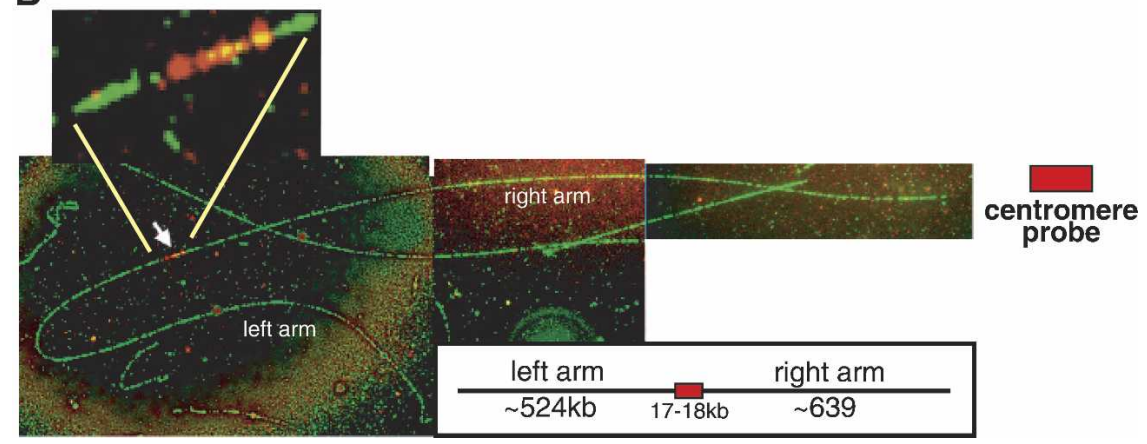

Figure 5. Fiber FISH analysis of a novel chromosome verifies its structure. The 403-535 unstable 1200-kb chromosome was excised from a pulsefield gel and subjected to fiber FISH analysis (see Materials and Methods). All ChrVII sequences were detected using a FITC modified probe (green). (A) A rhodamine-conjugated rightend probe (to the MES1 gene) detected two signals on the chromosome fiber. (B) A centromere-linked probe (see Materials and Methods) detected a single signal on each chromosome fiber of the novel chromosome. Between 20 and 100 full-length chromosome fibers were identified in both normal and unstable chromosome preparations for each analysis (see Materials and Methods). The size of chromosomes was calculated based on DNA stretching of 2.3 $\mathrm{kb} / \mathrm{\mu M}$. 


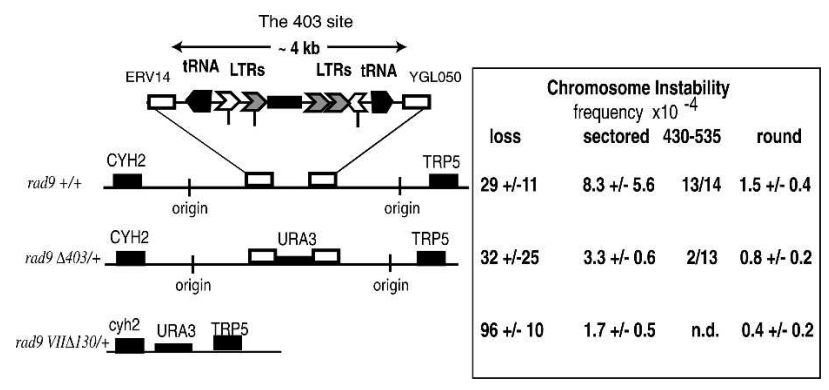

Figure 6. Deletions of the ChrVII 403 E2 site decrease chromosome instability. The diagram shows sequence elements in the 403 E2 site. Indicated with symbols is the location and orientation of transcription of tRNA genes, LTR $\sigma$ (open chevron) and $\delta$ (gray chevron) elements, three mitochondrial sequences (black box), two origins of replication at 393,919 and 418,930 , and sites of recombination breakpoints (vertical marks). In the rad9 $\Delta 4 /+$, the region between ERV14 and YGLO50 is deleted. Frequencies and standard deviations were determined from at least six cultures for each strain. The frequencies of sectored colonies between rad9 and rad9 $\Delta 403 /+$ are significantly different as determined by a $\chi^{2}$ test to the $P=0.05$ confidence level. The number of sectored colonies that contained the 403-535 translocation was determined by PCR (see Materials and Methods).

LTR repeat fragments, and three mitochondrial sequences. We tested if any of these sequences might cause instability by deleting them. The frequency of sectored colonies in the rad9 $\Delta 403 /+$ strain was reduced $\sim 2.5$-fold compared with the original rad9 strain, and round recombinants were also reduced about twofold, while loss appeared unchanged. By using the qualitative PCR test, we found that $+/+$ sectored colonies usually contained a 403-535 translocation (13 out of 14 ), while $\Delta 403 /+$ sectored colonies usually did not contain the 403-535 translocation (two out of 13), suggesting that sectored colonies in the $\Delta 403 /+$ strain are usually formed using different sequences.

Because instability was reduced but not eliminated in the rad9 $\Delta 403 /+$ strain, other sites that cause instability must be present on the chromosome. Deletion of the 403 sites on both homologs did not significantly reduce the frequency of instability below that of the $\Delta 403 /+$ strain (data not shown). We therefore deleted most of the E2 genetic interval on the CAN1-containing homolog $($ rad9s $\Delta 130)$ and found that this larger deletion further reduced the frequency of sectored and mitotic recombinants four- to fivefold (cf. rad9 VII $130 \mathrm{~kb}$ and rad9) (Fig. 6). A precise interpretation of the reduction of genetic instability by the larger deletion is complicated by the fact that the larger deletion also increased the frequency of chromosome loss. Altogether, we conclude that the 403 site causes formation of $>60 \%$ of the unstable chromosomes, and regions outside of the 403 site cause a minor but still significant number of unstable chromosomes.

\section{The disruption of DNA replication induces unstable chromosomes}

To understand which DNA sequence elements in the 403 site might cause instability, we sought experimental conditions that would enhance instability. Since the instability of mammalian fragile sites is increased when DNA replication was disrupted (Richards 2001), we tested the idea that instability of the 403 site might also be increased by the disruption of DNA replication. We disrupted DNA replication globally by treating yeast cells briefly with hydroxyurea (HU) to lower dNTP levels, or by introducing an rrm3 mutation into our strains that increases stalling of DNA replication forks at many sites in the genome (Rrm3 is a DNA replication helicase) (Ivessa et al. 2002). Strikingly, we found that both HU treatment and an $\mathrm{rrm} 3$ mutation increased instability by threefold to 20 -fold in $R A D^{+}$and in rad9 mutants (sectored colonies) (Table 1). The increased instability involved formation of unstable E2 chromosomes and specifically the 403-535 unstable chromosomes (two of 21 HU-induced unstable strains contained a diagnostic 4-kb HpaI junction fragment) (data not shown). The simplest interpretation of these results is that a sequence element

Table 1. Frequencies of cells with chromosome loss, stable round recombinants, and unstable sectored recombinants

\begin{tabular}{|c|c|c|c|c|c|c|}
\hline & Chromosome loss & Normalized & Stable rec (round) & Normalized & Unstable rec (sectored) & Normalized \\
\hline$R A D^{+}$ & $5.1 \times 10^{-4} \pm 0.6$ & 1 & $1.3 \times 10^{-4} \pm 1.3$ & 1 & $0.16 \times 10^{-4} \pm 0.09$ & 1 \\
\hline$R A D^{+} \operatorname{rrm} 3$ & $8.4 \times 10^{-4} \pm 7.8$ & 1.6 & $2.8 \times 10^{-4} \pm 2.3$ & 2.2 & $1.3 \times 10^{-4} \pm 0.6$ & 8.2 \\
\hline$R A D^{+} \operatorname{sml1}$ & $8.9 \times 10^{-4} \pm 6.6$ & 1.7 & $2.3 \times 10^{-4} \pm 2.2$ & 1.7 & $0.07 \times 10^{-4} \pm 0.03$ & 0.4 \\
\hline$R A D^{+}+H U$ & $51 \times 10^{-4} \pm 2.5$ & 10 & $13.5 \times 10^{-4} \pm 4.1$ & 10 & $3.6 \times 10^{-4} \pm 0.25$ & 22.5 \\
\hline rads & $45 \times 10^{-4} \pm 24$ & 8.8 & $1.6 \times 10^{-4} \pm 0.6$ & 1.2 & $6.2 \times 10^{-4} \pm 3.4$ & 39 \\
\hline rad9 $\mathrm{rrm} 3$ & $439 \times 10^{-4} \pm 570$ & 86 & $5.8 \times 10^{-4} \pm 2.0$ & 4.5 & $21.7 \times 10^{-4} \pm 3.0$ & 135 \\
\hline rad9 sml1 & $48 \times 10^{-4} \pm 51$ & 9.4 & $1.3 \times 10^{-4} \pm 0.6$ & 1.0 & $3.8 \times 10^{-4} \pm 1.0$ & 24 \\
\hline $\operatorname{rad} 9+\mathrm{HU}$ & $650 \times 10^{-4} \pm 18$ & 127 & $24.6 \times 10^{-4} \pm 4.8$ & 19 & $31.5 \times 10^{-4} \pm 12.5$ & 197 \\
\hline $\operatorname{rad} 17$ & $93 \times 10^{-4} \pm 51$ & 18 & $20.5 \times 10^{-4} \pm 16$ & 16 & $75 \times 10^{-4} \pm 57$ & 469 \\
\hline rad17 sml1 & $180 \times 10^{-4} \pm 140$ & 35 & $16.0 \times 10^{-4} \pm 8.0$ & 12 & $55 \times 10^{-4} \pm 23$ & 344 \\
\hline mec1 sml1 & $71 \times 10^{-4} \pm 40$ & 14 & $7.2 \times 10^{-4} \pm 6.5$ & 5.5 & $37 \times 10^{-4} \pm 9$ & 231 \\
\hline mec1-100 & $20 \times 10^{-4} \pm 20$ & 3.9 & $1.8 \times 10^{-4} \pm 1.3$ & 1.4 & $10.9 \times 10^{-4} \pm 6.2$ & 68 \\
\hline mrc1 & $8.3 \times 10^{-4} \pm 5.9$ & 1.6 & $2.9 \times 10^{-4} \pm 1.5$ & 2.2 & $1.7 \times 10^{-4} \pm 1.2$ & 10.6 \\
\hline
\end{tabular}

See Materials and Methods for strain numbers. All frequencies were calculated from five to 10 duplicate cultures. Frequencies were normalized to $R A D$. 
in the 403 site disrupts DNA replication to precipitate instability.

\section{Checkpoint proteins suppress the formation of unstable chromosomes}

To further test the role of DNA replication and a parallel of the 403 site's instability to that of mammalian fragile sites, we determined if unstable chromosomes are formed more frequently in replication checkpoint mutants. As previously mentioned, defects in the ATR and BRCA1 replication checkpoint proteins increase instability of mammalian fragile sites (Casper et al. 2002; Arlt et al. 2004). In Figure 1B, we showed that defects in $R A D 9$ increase the frequency of unstable chromosomes. We also found that mutations in $M E C 1$, the yeast ortholog of the mammalian Atr gene, RAD17, which encodes a component of the checkpoint sliding clamp, and $M R C 1$, which encodes another S-phase-specific checkpoint protein, each increased instability (Table 1). The fact that mec1 sml1 and rad17 mutants generated an even higher frequency of unstable cells than did rads mutants suggests that instability is linked to defects in DNA replication (because Mec1 and Rad17 have more prominent roles in DNA replication than does Rad9). A mec1-100 mutant with a less-severe defect in S-phase controls than a mec1-null mutation has a lower frequency of instability (Paciotti et al. 2001). Consistent with the model that a defect in S-phase controls leads to instability, we found that an mrc1 mutant with defects in S-phase controls and no defect in the G2 checkpoint (Alcasabas et al. 2001) showed an increased frequency of unstable chromosomes (Table 1).

To test the effect of the mec1 mutation on instability, we used a mec1 sml1 double mutant; the sml1 mutation is needed to suppress the lethality of a mec1-null mutation (Zhao et al. 1998; Paulovich et al. 1999). We considered the possibility that the sml1 mutation might itself affect chromosome instability, an especially reasonable hypothesis given that Smll regulates dNTP synthesis needed for efficient DNA replication (Smll negatively regulates ribonucleotide reductase such that $s m 11 \mathrm{mu}-$ tants have approximately twofold higher levels of dNTPs than do $S M L 1^{+}$strains) (Zhao and Rothstein 2002). An sml1 mutation has been shown to increase instability involving base-pair changes (Chabes et al. 2003), and in another study it suppressed DNA fork stalling and breakage (Cha and Kleckner 2002) (see Discussion). In the ChrVII assay, we found that an sml1 mutation caused a modest decrease in chromosome instability in rad9 mutants, and a complex though also modest change in the stability of rad17 mutants (Table 1). We conclude that the increased instability in mec1 sml1 strains reflects an important role for Mec1 in suppressing the formation of unstable chromosomes.

\section{Discussion}

Here we describe cycles of chromosome instability of a normal yeast chromosome. This study was prompted by the initial observation that sectored colonies are generated after selection for loss of a genetic marker on a ChrVII disome. The molecular events underlying the cycles of instability can be inferred from genetic analyses, and from analysis of one unstable chromosome. Analyses of cycles of instability lead to two principal conclusions. First, cycles of instability are increased by the disruption of DNA replication at specific chromosomal sites (fragile sites) and are normally suppressed by checkpoint controls. This conclusion comes from the observations that instability was increased in cells with low levels of dNTP, with defects in a replication helicase (Rrm3), and with defects in replication checkpoint controls (Table 1). In addition, instability frequently involved a site that contains multiple tRNA genes capable of stalling DNA replication (Supplementary Fig. S2), and when this site was deleted, the frequency of unstable chromosomes was reduced (Figs. 4, 6).

A second conclusion from this study is that cycles of instability involve the formation of unstable chromosomes. We do not know the structures of most unstable chromosomes, but the one whose structure we do know proved very informative. The one translocation, the $403-$ 535 chromosome, was formed by multiple nonallelic recombination events (Fig. 4), and its continued instability appeared linked to the recombination junction of the translocation (Fig. 2D) (see below). We suggest that the new translocation junction may be unstable because it juxtaposes chromosomal regions that are inherently "incompatible."

These results, together with many observations in the literature discussed below, suggest a model for cycles of chromosome instability (Fig. 7). In this model, instability begins at chromosomal elements that disrupt DNA replication (asterisk). Once replication forks stall, those sites break unless stabilized by checkpoint proteins. Broken chromosomes give rise to either stable chromosomes and cells or unstable chromosomes and cells. Stable cells are formed either by chromosome loss or by allelic recombination, telomere addition, or stable translocations to convert the chromosome into a stable form. In this study, we detected loss and allelic recombination but not telomere addition or stable translocations. We suggest the latter two events occur less frequently and thus we have not yet detected them. Cells with unstable chromosomes are formed by nonallelic recombination events to form either a monocentric or a dicentric chromosomal translocation. We suggest that mono- and dicentric chromosomal translocations remain unstable either because they have two centromeres (forming dicentrics) or because they contain an unstable translocation junction that joins two "incompatible" regions of the genome (see below).

\section{Might tRNA genes disrupt DNA replication to initiate} instability?

We propose that one element that may cause instability of the 403 E2 site, the putative dicentric and the monocentric translocations, is tRNA genes. This hypothesis is 


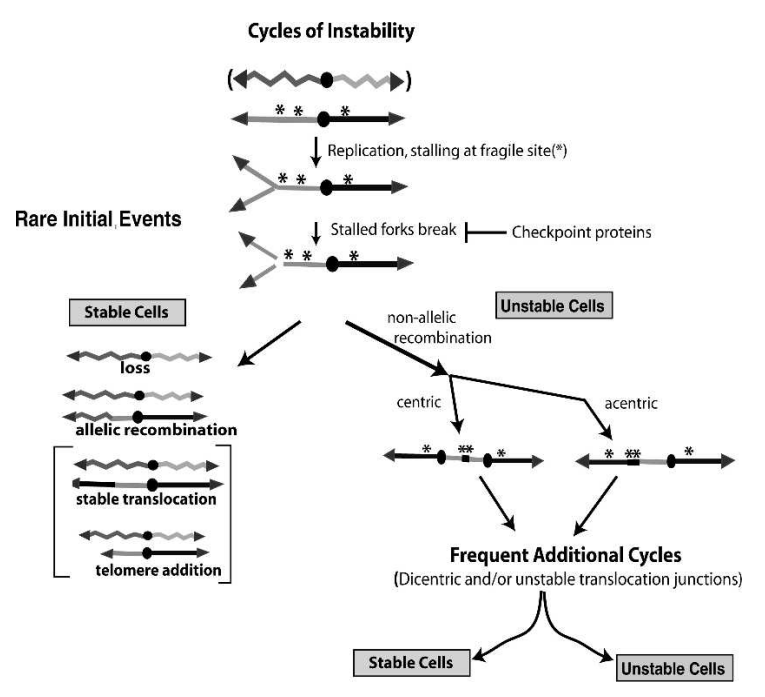

Figure 7. Cycles of chromosome instability arising from fragile sites. Two chromosome homologs are shown as a jagged line and a straight line. The DNA replication and instability of only one homolog is shown. Instability begins when DNA replication stalls at the fragile sites $\left({ }^{\star}\right)$ and break unless suppressed by checkpoint proteins. Broken chromosomes generate either stable or unstable cells. Stable cells form when the broken chromosome is either lost, undergoes allelic recombination with a homolog, or undergoes nonallelic recombination to form a stable translocation, or when telomere sequences are added. Unstable cells are formed if the broken chromosome undergoes nonallelic recombination joining two fragile sites. Recombination generates either an acentric (not shown), a monocentric, or a dicentric chromosome. The dicentric chromosome may be unstable because it undergoes breakage-fusion-bridge cycle events $(\mathrm{BFB})$ or because of its translocation junction $\left({ }^{\star \star}\right)$. See text for discussion.

supported by correlative evidence; both the 403 and 535 sites contain several tRNA genes, as do the putative dicentric and monocentric 403-535 translocations (Figs. 4B, 6; Supplementary Fig. S3). Other sequence elements in the 403 and 535 sites, namely, LTRs and mitochondrial sequence fragments, probably did not cause instability, as discussed below. Observations from other studies lend strong support to the hypothesis that tRNA genes cause instability; tRNA genes in yeast stall DNA replication, are associated with DNA breaks, and activate checkpoint control responses (Deshpande and Newlon 1996; Ivessa et al. 2003). In addition, Cha and Kleckner (2002) reported that specific regions on Chromosome III (ChrIII) were prone to breakage in mec1 checkpoint mutant cells, and several of these regions contain clusters of tRNA genes. These regions of the chromosomes also slowed DNA replication forks. We found that the two tRNA genes in the 403 E2 site are associated with stalled replication forks (see Fig. 6; Supplementary Fig. S2; Friedman and Brewer 1995). If one or both of these tRNA genes also cause instability, they probably do so in conjunction with the direction of DNA replication; only tRNA genes transcribed into an oncoming replication fork stall that fork (Deshpande and Newlon 1996). Instability may thus be due to both the presence of tRNA genes and directionality of DNA replication, and may involve other factors as well. For example, the preferential fusion of 403 and 535 sites may be enhanced by their localization to the nucleolus, where tRNA genes reside (Thompson et al. 2003) or they may colocalize as sites of DNA damage (Lisby and Rothstein 2004). A mammalian oncogene fuses with a regulatory sequence following their colocalization (Nikiforova et al. 2000).

It is likely that the phenomenon of replication fork stalling causing instability can be caused by other chromosomal elements as well (i.e., replication origins, heterochromatin). In yeast, the ChrVII E1 region is unstable but contains only one tRNA gene, and three sites on ChrIII prone to breakage do not contain any tRNA genes (Cha and Kleckner 2002).

\section{The behavior of unstable chromosomes is probably not due to dicentric behavior}

The dramatic behavior of unstable chromosomes documented in Figure 2 is reminiscent of that of dicentric chromosomes (Neff and Burke 1992; Brock and Bloom 1994). Some unstable chromosomes may, indeed, contain dicentrics (Fig. 4B; Supplementary Fig. S3). We think it unlikely, however, that dicentrics explain the behavior of unstable chromosomes because the 403-535 translocation is unstable even though it is monocentric. In addition, both the 403-535 chromosome and the putative dicentric intermediate appear to undergo rearrangements involving their translocation junctions, a behavior not expected if the chromosomes are breaking because they are dicentrics. We cannot formally rule out the possibility that the 403-535 chromosome may be a dicentric chromosome (see Platero et al. 1999 for uncovering of a cryptic centromere in Drosophila), but that seemingly remote possibility, and having to explain breakage in the fusion junctions, renders such an explanation less likely. We therefore suggest that instability of unstable intermediates may frequently be due to the sequences in the translocation junctions.

LTR and mitochondrial sequence fragments in the 403 site reveal a history of instability

The 403 E2 site contains four LTR and three mitochondrial sequence fragments (and one full-length LTR). Fulllength LTR sequences are normally part of the ends of retrotransposons (Kim et al. 1998), and mitochondrial sequences are obviously normally in the mitochondrial genome. How, then, did so many LTR and mitochondrial sequence fragments arrive in the 403 E2 site? Interestingly, it has been shown that both LTR and mitochondrial sequence fragments (and not full-length LTRs) insert into sites of double-stand breaks as a mechanism of DNA repair (Moore and Haber 1996; Ricchetti et al. 1999). This suggests that LTR and mitochondrial sequence fragments mark genomic sites prone to breakage. This suggests that the 403 E2 site has been a particularly active site of DNA breaks during the evolution of 
Saccharomyces cerevisiae. Further evidence that the 403 E2 site has been remarkably unstable evolutionarily comes from genome sequence comparisons of four species of Saccharomyces (Kellis et al. 2003). Kellis et al. reported that the 403 site on ChrVII was the only nontelomeric region in S. cerevisiae that contained gene sequence features suggesting segmental translocation and rapid genetic change. We uncovered the fragility of this site fortuitously in choosing ChrVII to access chromosome behavior in checkpoint mutants (Carson and Hartwell 1985; Weinert and Hartwell 1990).

The origins of LTR fragments near tRNA genes has previously been ascribed not to DNA breaks arising from the disruption of DNA replication but rather to the association of the retrotransposon integrase with PolIII RNA polymerase during transposition (Kim et al. 1998). Association of the integrase with PolIII may direct the integrase to cleave a DNA site into which the transposon inserts. This integrase-PolIII association might account for the striking observation that $\sim 90 \%$ of LTR sequence fragments in the yeast genome are found near and nearly always upstream of tRNA genes. There are therefore two hypotheses for why LTR fragments are found upstream of tRNA genes: either because replication forks stall and break near tRNA genes (see above), or because retrotransposon integrase interacts with PolIII to direct integrase. These two models may be reconciled in a single model if integrase associates most efficiently with PolIII in the presence of stalled replication forks, and integrase may then even contribute to fork breakage, and thus its instability.

\section{Checkpoint proteins may suppress instability by stabilizing replication forks and by regulating recombination pathways}

We found that mec1, rad17, mrc1, and rad9 mutants have higher frequencies of many forms of instability than do wild-type cells (Table 1), consistent with previous reports (Weinert and Hartwell 1990; Klein 2001; Craven et al. 2002). Mec1, Rad17, Mrc1, and Rad9 may have two roles in suppressing instability. First, they may preserve the stability of replication forks; for example, Mec1 has been shown to preserve the structure of stalled forks and their capacity to resume replication, and the instability in mec1 mutants is very high (Table 1; Lopes et al. 2001; Tercero and Diffley 2001). The exact roles of Mec1, Rad17, Mrc1, and Rad9 in replication fork biology are unknown, though Mrcl and Rad9 individually may play less of a role and correspondingly show a lower frequency of unstable chromosomes than does Mec1 (Table 1). A second role for these checkpoint proteins may involve regulation of recombination pathways (Grushcow et al. 1999|. Checkpoint proteins phosphorylate the single-strand binding protein Rpa (Brush et al. 1996) and Rad55 (Bashkirov et al. 2000), and regulate cohesion function (Unal et al. 2004), and by these or other mechanisms, checkpoint proteins may influence recombination pathways and the fate of broken chromosomes.
The fates of broken chromosomes from other yeast chromosome studies

Several studies in budding yeast suggest that instability in checkpoint-defective cells results in allelic mitotic recombination, chromosome loss, nonallelic chromosome translocations, and chromosome truncations with telomere addition (see Fig. 7; Myung et al. 2001; Kolodner et al. 2002; Lemoine et al. 2005). We and others have detected instability resulting in allelic recombination and chromosome loss, but we have not detected stable translocations or truncations with telomere additions. On the other hand, Myung, Kolodner, and colleagues (Klein 2001; Myung et al. 2001; Craven et al. 2002; Kolodner et al. 2002) have detected instability resulting in stable translocations and truncations with telomere additions, though they could not detect chromosome loss or mitotic recombinants because their assay used a haploid yeast strain. To reconcile results from these different studies and systems, we suggest that a broken chromosome may undergo rearrangements that most frequently lead to chromosome loss, allelic recombination, and nonallelic recombination leading to unstable chromosomes, and less frequently to stable translocations and truncations with telomere additions. The Myung and Kolodner studies allow detection of only the most rare events, while the assay here detects the more frequent events, making detection of the rarer stable translocations and telomere additions difficult.

\section{Unstable chromosomes, fragile sites, and cancer}

The behavior of mammalian fragile sites clearly resembles that of some yeast sites (including the 403 E2 site reported here and sites on ChrIII described by Cha and Kleckner [2002] and Lemoine et al. [2005]). Both yeast and mammalian fragile sites break and/or rearrange following the disruption of DNA replication unless suppressed by Mec1 and Rad9 or their mammalian counterparts Atr and Brcal (Casper et al. 2002; Arlt et al. 2004). The linkage of specific fragile sites to cancer underscores the importance of the regulation of DNA replication to prevent cancer (Coquelle et al. 1997; Hellman et al. 2002). Both yeast and mammalian sites appear to be associated with specific chromosomal elements (tRNA genes in yeast [this study], Ty elements [Lemoine et al. 2005], and simple repeat sequences in mammals [Richards 2001]). There is a plausible hypothesis to explain how tRNA genes in yeast disrupt DNA replication (Deshpande and Newlon 1996; Ivessa et al. 2003), though there is little understanding of how mammalian sites disrupt DNA replication and cause instability.

It is widely held that mutations drive cancer cell development, and that some of those mutations likely involve chromosome rearrangements and loss (Vogelstein and Kinzler 2004). One prominent model of chromosome rearrangements posits that instability arises after telomere sequences erode, allowing chromosome fusions to generate dicentrics that undergo additional rounds of instability (the breakage-fusion-bridge cycle) (McClintock 
1984; Maser and DePinho 2002; Gisselsson et al. 2000). We propose here another model of instability that begins with the disruption of DNA replication and involves unstable chromosomes with unstable recombination joints that drive further instability (Fig. 7). Whether unstable monocentric translocations have a role in genome rearrangements in cancer is unknown, though some cancer cells do contain unstable translocations (Padilla-Nash et al. 2001).

\section{Materials and methods}

\section{Yeast strains}

All yeast strains are derivatives of the A364a strain 7225, renamed here TY200, described in a previous study (Weinert and Hartwell 1990). TY200 is a ChrVII disome that is MAT $\alpha$ +/hxk2::CAN1 lys5/+ cyh ${ }^{r} / C Y H^{s}$ trp5/+ leu1/+ Centromere ade6/++/ade3, ura3-52. Derivatives of this strain were made by transformation using DNA fragments. Genotypes were verified by Southern analysis, by PCR tests, and/or by cell phenotype. We obtained similar chromosome instability results for each of two independent mutants for each mutation. We transformed TY200 with a rad9::URA3 fragment or a rad17hisg::URA3 fragment to generate TY206 and TY216, respectively (Lydall and Weinert 1997). The instability of rad9 and rad17 mutants was complemented by plasmids that contained the wild-type genes (after generating Ura ${ }^{-}$strains by selection for $\mathrm{FOA}^{\mathrm{R}}$ ) (data not shown). The sml1 and $m r c 1$ deletions were generated by amplification of the $s m 11:: N E O$ and $m r c 1:: N E O$ deletions from the Yeast Deletion Strains using primers that flank each gene. Deletions of $M E C 1, R R M 3$, and regions from ChrVII were generated by cloning DNA fragments that flank the gene or region of interest into plasmid pRS406-URA3, targeting the plasmid into the genome, and selecting for $\mathrm{Ura}^{+}$transformants. The plasmids' general structure is REX-5'-flanking sequencepRS406URA $3^{+}-3^{\prime}$-flanking sequence-REX, where REX is a unique restriction site used to target the plasmid into the genome. The mec1::URA3 deletion contains a BamHI-SacII from Chromosome II (ChrII) base pairs 504,936-505,762 and a SacISacII from base pairs 512,647-513,104 in pRS406 to generate pWL71, which was targeted to the genome by digestion with XbaI (Gardner 1998). Insertion of mec1-100 was performed by subcloning an EcoRI-SacI DNA fragment from pML221.8 (Paciotti et al. 2001) into pRS406, and targeting it to the MEC1 locus with BclI (to introduce the mec1-100 allele and an Nterminal deletion of the second MEC1 allele). $\mathrm{Ura}^{+}$transformants were analyzed by HU sensitivity to identify correct integrants. A deletion of RRM3 contains sequences ChrVIII base pairs 170,487-170,819 and base pairs 172,903-173,263 (made by PCR amplification using appropriate primers) that flank $R R M 3$ on ChrVIII in pRS406 to generate p $\Delta$ rrm3, which was targeted into the genome by digestion with BamHI. To delete the 403 E2 site, the ERV14 and YGLO50 genes were amplified using primers from Research Genetics and cloned into pRS406 to generate $\mathrm{p} \triangle E R V 14-050$, which was targeted to the genome by digesting with SnaBI and BglII. We identified strains in which the 403 E2 site was deleted from the CAN1-containing homolog because in those strains chromosome loss led to simultaneous loss of the URA3 gene. To delete the 130-kb E2 genetic interval on ChrVII, we PCR-amplified and cloned DNA fragments for CYH2 $(311,278-311,510)$ and TRP5 $(447,845-448,725$ from ChrVII) in pRS406 to generate $\mathrm{p} \triangle C Y H 2-T R P 5$, which was targeted to the genome by digestion with BamHI. Strains containing a deletion of the E2 genetic interval from the CAN1-containing homolog were identified as described above. The $\triangle C Y H 2-T R P 5$ deletion eliminates $\mathrm{CYH} 2^{S}$ function (the other homolog is $c y h 2^{R}$ ) and leaves intact TRP5 $5^{+}$function. The strains are: $R A D^{+}$, TY200; $R A D^{+}$, sml1::neo, TY202; RAD , rrm3::URA3, TY204; rad9::ura3, TY206; rad9::ura3 sm11::neo, TY208; rad9::ura3 rrm3::URA3, TY210; rad9::ura3 VII $\Delta 4$ kb::URA3, TY212; rad9::ura3 VII $\Delta 130$ kb::URA3, TY214; rad17::hisg, TY216; rad17::hisg sml1::neo, TY218; mec1::URA3 sml1::neo, TY220; mrc1::neo, TY222; mec1-100:: URA3, TY224.

To analyze strains for chromosome instability, cells were grown on synthetic media lacking adenine to ensure selection for both ChrVII homologs. We sometimes also grew cells on media with glycerol as a carbon source to eliminate petites. The media that selected for chromosome loss and mitotic recombinants consisted of synthetic media supplemented with $60 \mu \mathrm{g} /$ $\mathrm{mL}$ canavanine and all essential amino acids except arginine and serine. The media that selected only for mitotic recombinants consisted of synthetic media supplemented with $60 \mu \mathrm{g} /$ $\mathrm{mL}$ canavanine and essential amino acids except arginine, serine, and adenine. Rich media consisted of YEPD, and synthetic media were as described (Sherman et al. 1986). The carbon source was $2 \%$ dextrose in all experiments. Cells were grown routinely at $30^{\circ} \mathrm{C}$.

\section{Selection of chromosome loss and mitotic recombinants}

To determine the frequencies of cells that had undergone chromosome changes and lost the CAN1 gene, cells were grown on rich media plates (YEPD) to allow cells to form that incurred chromosome changes. After 2-3 d of growth, cells from single colonies were resuspended in water, counted, plated on appropriate selective media, and incubated for 5-7 d to allow formation of colonies. Chromosome loss events were distinguished from mitotic recombinants by replica-plating to media without adenine. Mitotic recombinants were also analyzed by replicaplating onto solid media that lacked specific amino acids or that contained cycloheximide at $10 \mu \mathrm{g} / \mathrm{mL}$. (To aid in identification of E1 recombinants, we also used media with cycloheximide without adenine.) The phenotypes of the two types of chromosome loss events were verified by their His phenotypes; colonies with simple loss $\left(A D E 3^{+}\right.$ade $\left.^{-}\right)$are $\mathrm{His}^{+}$, while cells with loss coupled to recombination $\left(A D E 6^{+} a_{d e 3^{-}}\right)$are $\mathrm{His}^{-}$(see Fig. 1).

Frequencies for each strain were determined typically from analysis of six to 12 colonies, and the average and standard deviations are shown. We occasionally identified "jackpot" cultures in which most of the cells from a particular colony were $\mathrm{Can}^{\mathrm{R}}$; in these colonies, the founder cell most likely underwent a chromosomal event early during the growth of the colony. Jackpot cultures were not included in calculation of frequencies (e.g., two of 12 rad9 colonies originally tested for the data shown in Fig. 1B were jackpot cultures). The relative frequencies of events we report for rad9 and mec1 mutants are consistent with the relative rates of events reported previously (Weinert and Hartwell 1990; Craven et al. 2002).

To determine the frequencies of instability after treatment with $\mathrm{HU}$, cells were grown to a density of $\sim 5 \times 10^{6} / \mathrm{mL}$ in synthetic media without adenine, lysine, tryptophan, and leucine to select for cells with intact ChrVII homologs. Cells were then grown overnight $(\sim 16 \mathrm{~h})$ in rich media supplemented with HU $(0.1 \mathrm{M})$, washed to remove $\mathrm{HU}$, allowed to recover by growth in YEPD media for 6-8 $\mathrm{h}$ (to lose the Can 1 protein from genotypically can $1^{-}$cells), counted, and plated to determine cell viability and chromosome instability. 


\section{Lineage analysis}

Cells from sectored or round colonies were resuspended in water and counted, and typically 50-200 cells were plated on rich media analytical plates that then formed single colonies. After 2-3 d of growth, the colony phenotypes were determined by replica plating onto synthetic media or they were resuspended into microtiter wells and replica-pinned onto selective media. In extended lineage analyses as shown in Figure 2C, colonies that contained recombinant chromosomes were identified and their cells were resuspended, counted, plated on tertiary analytical plates, and allowed to form colonies whose phenotypes were determined.

\section{Molecular analysis of altered chromosomes}

To identify altered chromosomes, cells from sectored colonies were typically grown for $\sim 30 \mathrm{~h}$ in rich or synthetic media lacking adenine. Media lacking adenine may be more efficient in recovering cells that retain the unstable, altered chromosome. Altered chromosomes were converted to the normal mitotic recombinants when cells were grown for too many cell divisions before DNA preparation. Chromosomes were separated by pulsefield gels (Iadonato and Gnirke 1996) using conditions that optimize for separation of 1100- and 1200-kb chromosomes. We performed Southern hybridizations using DNA probes isolated from $\lambda$ phage or from DNA fragments amplified from the genome by PCR using appropriate primers. In Figure 3A, the ERV14 probe contains the sequences from 399,643 to 403,899 on ChrVII present in phage 70152 . The ADE3 probe consists of a 5-kb BamHI-SalI DNA fragment from plasmid pSC101. $\lambda$ phages were obtained from ATCC. In Figure 3B, chromosomes were probed with the ERVI4 or YGLO50 probes, both prepared by PCR using primers from Research Genetics.

The breakpoints of three isochromosomes were determined using a "bubble PCR" strategy (Ross-Macdonald et al. 1999). Briefly, we isolated genomic DNA from sectored colonies, digested it with HpaI to form blunt ends, ligated the bubble PCR fragment to the HpaI-digested DNA, and PCR-amplified DNA using a primer to YGLO5O (available upon request) and the appropriate "bubble" PCR primer.

Fiber FISH of a normal and altered ChvVII was performed as described elsewhere (Wang et al. 1996). Briefly, whole chromosomes were isolated from a pulsefield gel run in low-melting agarose that was not stained with $\mathrm{EtBr}$ (to prevent breaking during subsequent manipulations). The agarose plugs were excised, the agarose was melted, and the DNA solution was applied to a siliconized glass slide, covered with a round coverslip; liquid was allowed to slowly dehydrate. Chromosomes attach by their ends to the glass slide, and become stretched by capillary action generated during slow dehydration. This results in the uniform stretching of DNA to $2.3 \mathrm{~kb} / \mu \mathrm{M}$. The coverslip was removed, samples were oxidized to allow DNA binding to the slide, and DNA hybridization was carried out using fluorescently labeled DNA probes. A probe to the entire normal ChrVII sequence was generated using biotin-dUTP and the normal ChrVII as template, and biotin was detected with FITC-conjugated avidin. Other probes typically are $\sim 15 \mathrm{~kb}$ in length and were made using dioxygenin-dNTPs that were subsequently detected using rhodamine-conjugated antibodies to dioxygenin. The right-end probes were made using DNA from $\lambda$ phage 70148 that contains $15 \mathrm{~kb}$ of DNA surrounding the MES1 gene, the centromere probe using DNA from phage 70464, and a breakpoint centromere-proximal probe using DNA from phage 70669. After hybridization with fluorescently labeled probes, fields of fibers were scanned and 20-100 full-length fibers were identified in each sample and patterns of fluorescence noted.
A qualitative PCR assay to detect the 403-535 translocation chromosome was developed as follows. Primers that amplify only the translocation junction were from the 403 region $(405,805-405,786)$ and the 535 region $(535,600-535,575)$. Control primers were to YGL047 obtained from Research Genetics. We used the translocation primers at $500 \mathrm{nM}$ and the control primers at $63 \mathrm{nM}$ in a multiplex reaction to maximize detection of the translocation and the control PCR fragment and minimize competition between them. PCR conditions included a $50^{\circ} \mathrm{C}$ annealing step and 30 cycles of amplification for $1 \mathrm{~min}$ each cycle.

\section{Acknowledgments}

We thank Bonny Brewer and Margaret Hoang for their help in the 2D gel analysis (Supplementary Fig. S2). We thank Kathleen Dixon, Carol Gregorio, and Alison Adams for their assistance and advice in assembling this manuscript. We also thank C. Putnam, K. Nyberg, and R. Michelson for frequent discussions of this work. This work was supported by grants from the March of Dimes, NSF (\#0222193), and NIH (GM045276) to T.W.

\section{References}

Alcasabas, A.A., Osborn, A.J., Bachant, J., Hu, F., Werler, P.J., Bousset, K., Furuya, K., Diffley, J.G.X., Carr, A.M., and Elledge, S.J. 2001. Mrc1 transduces signals of DNA replication stress to activate Rad53. Nat. Cell Biol. 3: 958-965.

Arlt, M.F., Xu, B., Durkin, S.G., Casper, A.M., Kastan, M.B., and Glover, T. 2004. BRCA1 is required for common-fragile-site stability via its G2/M checkpoint function. Mol. Cell. Biol. 24: 6701-6709.

Bashkirov, V.I., King, J.S., Bashkirova, E.V., Schmuckli-Maurer, J., and Heyer, W.D. 2000. DNA repair protein Rad55 is a terminal substrate of the DNA damage checkpoints. Mol. Cell. Biol. 20: 4393-4404.

Bitterman, K.J., Medvedik, O., and Sinclair, D.A. 2003. Longevity regulation in Saccharomyces cerevisiae: Linking metabolism, genome stability, and heterochromatin. Microbiol. Mol. Biol. Rev. 67: 376-399, table of contents.

Brock, J.A. and Bloom, K. 1994. A chromosome breakage assay to monitor mitotic forces in budding yeast. J. Cell Sci. $\mathbf{1 0 7}$ (Pt 4): 891-902.

Brush, G.S., Morrow, D.M., Hieter, P., and Kelly, T.J. 1996. The ATM homologue MEC1 is required for phosphorylation of replication protein A in yeast. Proc. Natl. Acad. Sci. 93: 15075-15080.

Carson, M.J. and Hartwell, L. 1985. CDC17: An essential gene that prevents telomere elongation in yeast. Cell 42: 249-257.

Casper, A.M., Nghiem, P., Arlt, M.F., and Glover, T.W. 2002. ATR regulates fragile site stability. Cell 111: 779-789.

Cha, R.S. and Kleckner, N. 2002. ATR homolog Mec1 promotes fork progression, thus averting breaks in replication slow zones. Science 297: 602-606.

Chabes, A., Georgieva, B., Domkin, V., Zhao, X., Rothstein, R., and Thelander, L. 2003. Survival of DNA damage in yeast directly depends on increased dNTP levels allowed by relaxed feedback inhibition of ribonucleotide reductase. Cell 112: 391-401.

Coquelle, A., Pipiras, E., Toledo, F., Buttin, G., and Debatisse, M. 1997. Expression of fragile sites triggers intrachromosomal mammalian gene amplification and sets boundaries to early amplicons. Cell 89: 215-225.

Craven, R.J., Greenwell, P.W., Dominska, M., and Petes, T.D. 
2002. Regulation of genome stability by TEL1 and MEC1, yeast homologs of the mammalian ATM and ATR genes. Genetics 161: 493-507.

de Lange, T. 2002. Protection of mammalian telomeres. Oncogene 21: 532-540.

. 2005. Shelterin: The protein complex that shapes and safeguards human telomeres. Genes \& Dev. 19: 2100-2110.

Desany, B., Alcasbas, A., Bachant, J., and Elledge, S. 1998. Recovery from DNA replication stress is the essential function of the S-phase checkpoint pathway. Genes \& Dev. 12: 29562970.

Deshpande, A.M. and Newlon, C.S. 1996. DNA replication fork pause sites dependent on transcription. Science 272: 10301033.

Eichler, E.E. and Sankoff, D. 2003. Structural dynamics of eukaryotic chromosome evolution. Science 301: 793-797.

Friedman, K.L. and Brewer, B.J. 1995. Analysis of replication intermediates by two-dimensional agarose gel electrophoresis. Methods Enzymol. 262: 613-627.

Galgoczy, D.J. and Toczyski, D.P. 2001. Checkpoint adaptation precedes spontaneous and damage-induced genomic instability in yeast. Mol. Cell. Biol. 21: 1710-1718.

Gardner, R.D. 1998. "Defining response pathways of budding yeast checkpoint genes." Ph.D. thesis, University of Arizona.

Gisselsson, D., Pettersson, L., Hoglund, M., Heidenblad, M., Gorunova, L., Wiegant, J., Mertens, F., Dal Cin, P., Mitelman, F., and Mandahl, N. 2000. Chromosomal breakagefusion-bridge events cause genetic intratumor heterogeneity. Proc. Natl. Acad. Sci. 97: 5357-5362.

Grushcow, J.M., Holzen, T.M., Park, K.J., Weinert, T., Lichten, M., and Bishop, D.K. 1999. Saccharomyces cerevisiae checkpoint genes MEC1, RAD17 and RAD24 are required for normal meiotic recombination partner choice. Genetics 153: 607-620.

Hellman, A., Zlotorynski, E., Scherer, S.W., Cheung, J., Vincent, J.B., Smith, D.I., Trakhtenbrot, L., and Kerem, B. 2002. A role for common fragile site induction in amplification of human oncogenes. Cancer Cell 1: 89-97.

Iadonato, S.P. and Gnirke, A. 1996. RARE-cleavage analysis of YACs. Methods Mol. Biol. 54: 75-85.

Ivessa, A.S., Zhou, J.Q., Schulz, V.P., Monson, E.K., and Zakian, V.A. 2002. Saccharomyces Rrm3p, a 5' to 3' DNA helicase that promotes replication fork progression through telomeric and subtelomeric DNA. Genes \& Dev. 16: 1383-1396.

Ivessa, A.S., Lenzmeier, B.A., Bessler, J.B., Goudsouzian, L.K., Schnakenberg, S.L., and Zakian, V.A. 2003. The Saccharomyces cerevisiae helicase Rrm3p facilitates replication past nonhistone protein-DNA complexes. Mol. Cell 12: 15251536.

Kastan, M.B. and Bartek, J. 2004. Cell-cycle checkpoints and cancer. Nature 432: 316-323.

Kellis, M., Patterson, N., Endrizzi, M., Birren, B., and Lander, E.S. 2003. Sequencing and comparison of yeast species to identify genes and regulatory elements. Nature 423: 241254.

Kim, J.M., Vanguri, S., Boeke, J.D., Gabriel, A., and Voytas, D.F. 1998. Transposable elements and genome organization: A comprehensive survey of retrotransposons revealed by the complete Saccharomyces cerevisiae genome sequence. Genome Res. 8: 464-478.

Klein, H.L. 2001. Spontaneous chromosome loss in Saccharomyces cerevisiae is suppressed by DNA damage checkpoint functions. Genetics 159: 1501-1509.

Kolodner, R.D. and Marsischky, G.T. 1999. Eukaryotic DNA mismatch repair. Curr. Opin. Genet. Dev. 9: 89-96.
Kolodner, R.D., Putnam, C.D., and Myung, K. 2002. Maintenance of genome stability in Saccharomyces cerevisiae. Science 297: 552-557.

Lemoine, F.J., Degtyareva, N.P., Lobachev, K., and Petes, T.D. 2005. Chromosomal translocations in yeast induced by low levels of DNA polymerase a model for chromosome fragile sites. Cell 120: 587-598.

Lisby, M. and Rothstein, R. 2004. DNA damage checkpoint and repair centers. Curr. Opin. Cell Biol. 16: 328-334.

Lopes, M., Cotta-Ramusino, C., Pellicioli, A., Liberi, G., Plevani, P., Muzi-Falconi, M., Newlon, C.S., and Foiani, M. 2001. The DNA replication checkpoint response stabilizes stalled replication forks. Nature 412: 557-561.

Lukas, J., Lukas, C., and Bartek, J. 2004. Mammalian cell cycle checkpoints: Signalling pathways and their organization in space and time. DNA Repair (Amst) 3: 997-1007.

Lydall, D. and Weinert, T. 1997. G2/M checkpoint genes of Saccharomyces cerevisiae: Further evidence for roles in DNA replication and/or repair. Mol. Gen. Genet. 256: 638-651.

Maser, R.S. and DePinho, R.A. 2002. Connecting chromosomes, crisis, and cancer. Science 297: 565-569.

McClintock, B. 1984. The significance of responses of the genome to challenge. Science 226: 792-801.

Moore, J.K. and Haber, J.E. 1996. Capture of retrotransposon DNA at the sites of chromosomal double-strand breaks. $\mathrm{Na}$ ture 383: 644-646.

Moore, I.K., Martin, M.P., Dorsey, M.J., and Paquin, C.E. 2000. Formation of circular amplifications in Saccharomyces cerevisiae by a breakage-fusion-bridge mechanism. Environ. Mol. Mutagen. 36: 113-120.

Myung, K., Datta, A., and Kolodner, R.D. 2001. Suppression of spontaneous chromosomal rearrangements by $S$ phase checkpoint functions in Saccharomyces cerevisiae. Cell 104: 397-408.

Neff, M.W. and Burke, D.J. 1992. A delay in the Saccharomyces cerevisiae cell cycle that is induced by a dicentric chromosome and dependent upon mitotic checkpoints. Mol. Cell. Biol. 12: 3857-3864.

Nikiforova, M.N., Stringer, J.R., Blough, R., Medvedovic, M., Fagin, J.A., and Nikiforov, Y.E. 2000. Proximity of chromosomal loci that participate in radiation-induced rearrangements in human cells. Science 290: 138-141.

Nyberg, K.A., Michelson, R.J., Putnam, C.W., and Weinert, T.A. 2002. Toward maintaining the genome: DNA damage and replication checkpoints. Annu. Rev. Genet. 36: 617-656.

Paciotti, V., Clerici, M., Lucchini, G., and Longhese, M.P. 2001. Characterization of mecl kinase-deficient mutants and of new hypomorphic mec1 alleles impairing subsets of the DNA damage response pathway. Mol. Cell. Biol. 21: 39133925.

Padilla-Nash, H.M., Heselmeyer-Haddad, K., Wangsa, D., Zhang, H., Ghadmimi, B.M., Macville, M., Augustus, M., Schrock, E., Hilgenfeld, E., and Ried, T. 2001. Jumping translocations are common in solid tumor cell lines and result in recurrent fusions of whole chromosome arms. Genes Chromosomes Cancer 30: 349-363.

Paulovich, A.G., Armour, C.D., and Hartwell, L.H. 1999. The Saccharomyces cerevisiae RAD9, RAD17, RAD24 and MEC3 genes are required for tolerating irreparable, ultraviolet-induced DNA damage. Genetics 150: 75-93.

Platero, J.S., Ahmad, K., and Henikoff, S. 1999. A distal heterochromatic block displays centromeric activity when detached from a natural centromere. Mol. Cell 4: 995-1004.

Ricchetti, M., Fairhead, C., and Dujon, B. 1999. Mitochondrial DNA repairs double-strand breaks in yeast chromosomes. Nature 402: 96-100. 
Richards, R.I. 2001. Fragile and unstable chromosomes in cancer: Causes and consequences. Trends Genet. 17: 339-345.

Ross-Macdonald, P., Sheehan, A., Friddle, C., Roeder, G.S., and Snyder, M. 1999. Transposon mutagenesis for the analysis of protein production, function, and localization. Methods Enzymol. 303: 512-532.

Santocanale, C. and Diffley, J.F. 1998. A Mec1- and Rad53-dependent checkpoint controls late-firing origins of DNA replication. Nature 395: 615-618.

Sherman, F., Fink, G.R., and Hicks, J.B. 1986. Methods in yeast genetics. Cold Spring Harbor Laboratory, Cold Spring Harbor, NY.

Tercero, J.A. and Diffley, J.F. 2001. Regulation of DNA replication fork progression through damaged DNA by the Mec1/ Rad53 checkpoint. Nature 412: 553-557.

Thompson, M., Haeusler, R.A., Good, P.D., and Engelke, D.R. 2003. Nucleolar clustering of dispersed tRNA genes. Science 302: 1399-1401.

Unal, E., Arbel-Eden, A., Sattler, U., Shroff, R., Lichten, M., Haber, J.E., and Koshland, D. 2004. DNA damage response pathway uses histone modification to assemble a doublestrand break-specific cohesin domain. Mol. Cell 16: 9911002.

van Steensel, B., Smogorzewska, A., and de Lange, T. 1998. TRF2 protects human telomeres from end-to-end fusions. Cell 92: 401-413.

Vogelstein, B. and Kinzler, K.W. 2004. Cancer genes and the pathways they control. Nat. Med. 10: 789-799.

Wang, M., Duelli, T., Gray, J., and Weier, H. 1996. High sensitivity, high resolution physical mapping by fluorescence in situ hybridization on to individual straightened DNA molecules. Bioimaging 4: 73-83.

Weinert, T.A. and Hartwell, L.H. 1990. Characterization of RAD9 of Saccharomyces cerevisiae and evidence that its function acts posttranslationally in cell cycle arrest after DNA damage. Mol. Cell. Biol. 10: 6554-6564.

Zhao, X. and Rothstein, R. 2002. The Dun1 checkpoint kinase phosphorylates and regulates the ribonucleotide reductase inhibitor Sml1. Proc. Nat1. Acad. Sci. 99: 3746-3751.

Zhao, X., Muller, E.G., and Rothstein, R. 1998. A suppressor of two essential checkpoint genes identifies a novel protein that negatively affects dNTP pools. Mol. Cell 2: 329-340.

Zhou, B.B. and Elledge, S.J. 2000. The DNA damage response: Putting checkpoints in perspective. Nature 408: 433-439. 


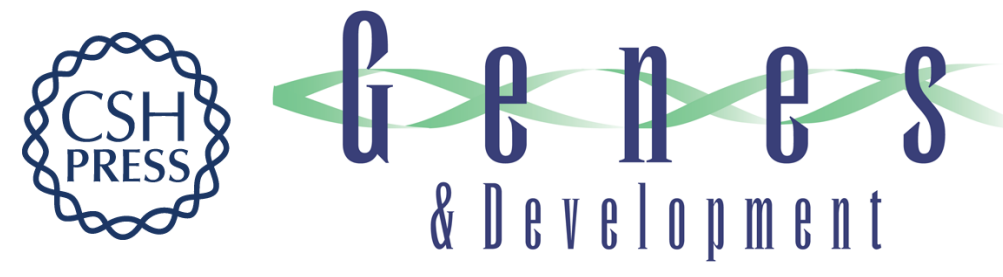

\section{Cycles of chromosome instability are associated with a fragile site and are increased by defects in DNA replication and checkpoint controls in yeast}

Anthony Admire, Lisa Shanks, Nicole Danzl, et al.

Genes Dev. 2006, 20:

Access the most recent version at doi:10.1101/gad.1392506

Supplemental Material

References

License

Email Alerting

Service
http://genesdev.cshlp.org/content/suppl/2005/12/29/gad.1392506.DC1

This article cites 60 articles, 26 of which can be accessed free at: http://genesdev.cshlp.org/content/20/2/159.full.html\#ref-list-1

Receive free email alerts when new articles cite this article - sign up in the box at the top right corner of the article or click here.

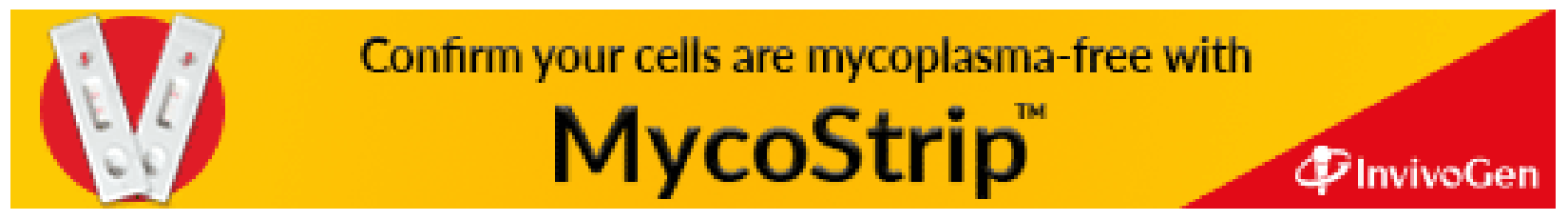

